Jurnal Media Agribisnis Vol. 2 No. 1 Tahun 2017 Hal 13 - 19

Media Komunikasi Hasil Penelitian Bidang Ilmu Agribisnis

ISSN 2541-6898

\title{
PENDAPATAN USAHATANI TANAMAN JAGUNG (Zea mays Sp) DI DESA RANTAU MAKMUR KECAMATAN BERBAK KABUPATEN TANJUNG JABUNG TIMUR
}

\author{
Rogayah $^{1^{*}}$, Hj.Wiwin Alawiyah ${ }^{2 *}$ dan Arfandi ${ }^{3 *}$ \\ ${ }^{1 *}$ Program Studi Agribisnis, Fakultas Pertanian Universitas Batanghari \\ ${ }^{2}$ Program Studi Agribisnis, Fakultas Pertanian Universitas Batanghari \\ Jl. Slamet Riyadi-Broni, Jambi. 36122. Telp. +6274160103 \\ ${ }^{3}$ Alumni Program Studi Agribisnis, Fakultas Pertanian Universitas Batanghari \\ *email korespondesi : wwnalawiyah78@gmail.com
}

\begin{abstract}
Tanjung Jabung Timur Regency has a predicate as the 4th planting area of corn commodities in Jambi Province. This provides an opportunity for farmers to focus their production in accordance with consumer demand and the business makes as a source of farmer income. Corn commodity development In Rantau Makmur Village, Berbak District has high economic value. The objective of this research is to know the description of farming activities, the use of input and production cost and the amount of income farming. The number of samples that taken in this study (30 farmers) applies simple random sampling methode. The results of this research note that the input productions used in this farming consisted of seeds, labors, fertilizer, pesticide/insecticide and several farm equipments. The used by the variety of bisi 2 were bought from an agriculture shop. male and female laborers come from inside and outside of their family. Fertilizer, pesticide/insecticide and equipment efforts by the farmer itself. It can be concluded that the amount of income of corn farming gives an average of Rp. 4.682.301,37/Ha/periode, or it is equivalent with Rp. 1.560.767,12/month of each family member. So it can be concluded that corn farming in Rantau Makmur Village, Berbak District Tanjung Jabung Timur Regency is still small lower than the region income standart of Rp. 2.020.000.
\end{abstract}

Keyword: Income, Farming, Corn.

\begin{abstract}
Abstrak
Kabupaten Tanjung Jabung Timur pengembangan komoditas jagung terluas peringkat ke 4 dalam Propinsi Jambi. Hal ini memberi peluang bagi petani jagung untuk memfokuskan produksinya pada jagung. Di Desa Rantau Makmur Kecamatan Berbak pengembangan komoditas jagung memiliki nilai ekonomis yang cukup tinggi. Penelitian ini dilakukan untuk melihat bagaimana gambaran tentang usahatani jagung, bagaimana penggunaan input dan biaya produksi, seberapa besar pendapatan usahataninya. Jumlah sampel yang diambil dalam penelitian ini adalah sebanyak 30 rumah tangga petani (RTP) secara acak sederhana (simple random sampling). Dari hasil penelitian diketahui bahwa input produksi yang digunakan terdiri dari bibit varietas bisi 2, tenaga kerja, pupuk, obat-obatan dan peralatan usahatani. Besarnya pendapatan usahatani adalah Rp. 4.682.301,37/Ha/MT, kalau dihitung perkapita dengan rata-rata jumlah anggota keluarga petani 3 orang maka besar pendapatan sebesar Rp. 1.560.767,12/Bln. Jadi dapat disimpulkan bahwa usahatani jagung di Desa Rantau Makmur Kecamatan Berbak Kabupaten Tanjung Jabung Timur masih kecil dari UMR sebesar Rp. 2.02.000 terhadap pendapatan keluarga petani.
\end{abstract}

Kata Kunci : Pendapatan, Usahatani, Jagung

Diterbitkan oleh Program Studi Agribisnis Fakultas Pertanian Universitas Batanghari Jambi Halaman. 13 
Jurnal Media Agribisnis Vol. 2 No. 1 Tahun 2017 Hal 13 - 19

Media Komunikasi Hasil Penelitian Bidang Ilmu Agribisnis

ISSN 2541-6898

\section{PENDAHULUAN}

Pengembangan sektor pertanian dalam arti luas harus di arahkan kepada sistem agribisnis dan agroindustri, karena pendekatan ini akan meningkatkan nilai tambah sektor pertanian, yang akhirnya akan meningkatkan pendapatan bagi pelaku pelaku agribisnis dan agroindustri. Perkembangan system agribisnis dan agroindustri akan berdampak terhadap pertumbuhan ekonomi daerah, meningkatkan pendapatan petani yang akhirnya diharapkan akan mengurangi ketimpangan pendapatan masyarakat. Untuk mewujudkan tujuan pengembangan ekonomi kerakyatan, terutama di sector pertanian maka perlu upaya untuk mempercepat pertumbuhan sector pertanian, khususnya peningkatan pendapatan dan kesejahteran masyarakat. Salah satu cara untuk mencapai tujuan tersebut adalah pengembangan agribisnis dan agroindustri yang terencana dengan baik (Soekortawi, 1990).

Kabupaten Tanjung Jabung Timur merupakan salah satu daerah dalam Provinsi Jambi yang memiliki lahan tanaman pangan terluas di Provinsi Jambi yaitu seluas 31,939 Ha (BPS Provinsi Jambi, 2015). Salah satu produk tanaman pangan yang dihasilkan dari daerah tersebut adalah jagung dengan luas tanam 898 Ha dengan hasil prosuksi sebesar 4.490 Ton dan produktivitas sebesar 5,00 ton/Ha pada tahun 2014 (BPS Tanjab Timur, 2015). Berikut data luas panen, prosuksi dan produktivitas jagung, menurut Kabupaten/Kota dalam Provinsi Jambi tahun 2014.

Tabel 1. Luas Panen, Produksi dan produktivitas Jagung menurut Kabupaten/Kota, Tahun 2014

\begin{tabular}{llccc}
\hline No & Kabupaten / Kota & $\begin{array}{c}\text { Luas Panen } \\
\text { (Ha) }\end{array}$ & $\begin{array}{c}\text { Produksi } \\
\text { (Ton) }\end{array}$ & $\begin{array}{c}\text { Produktivitas } \\
\text { (Ton/Ha) }\end{array}$ \\
\hline 1 & Kerinci & 1.821 & 12.036 & 6,61 \\
2 & Merangin & 338 & 1.570 & 4,64 \\
3 & Sarolangun & 134 & 580 & 4,33 \\
4 & Batanghari & 59 & 272 & 4,61 \\
5 & Muaro Jambi & 2755 & 15.300 & 5,55 \\
6 & Tanjung Jabung Timur & $\mathbf{8 9 8}$ & $\mathbf{4 . 4 1 7}$ & $\mathbf{4 , 9 2}$ \\
7 & Tanjab Barat & 746 & 3.208 & 4,30 \\
8 & Tebo & 105 & 486 & 4,63 \\
9 & Bungo & 1.041 & 5.530 & 5,31 \\
10 & Kota Jambi & 70 & 306 & 4,37 \\
11 & Sungai penuh & 69 & 329 & 4,77 \\
\hline & Jumlah & 8.036 & 44.034 & \\
& Rata-rata & 730 & 4003,10 & 5,48 \\
\hline
\end{tabular}

Sumber : Badan Pusat Statistik Provinsi Jambi (2015)

Dari data pada Tabel 1 di ats menunjukkan bahwa Kabupaten Tanjung Jabung Timur menduduki peringkat ke-4 dalam Provinsi Jambi sebagai daerah penghasil jagung. Hampir seluruh daerah Kecamatan dalam Kabupaten Tanjung Jabung Timur berkontribusi sebagai penghasil jagung. Data luas panen, produksi dan produktivitas tanaman jagung perKecamatan dalam wilayah Kabupaten Tanjung Jabung Timur disajikan pada Tabel 2. 
Jurnal Media Agribisnis Vol. 2 No. 1 Tahun 2017 Hal 13 - 19

Media Komunikasi Hasil Penelitian Bidang Ilmu Agribisnis ISSN 2541-6898

\begin{tabular}{|c|c|c|c|c|}
\hline No & Kabupaten / Kota & $\begin{array}{l}\text { Luas Panen } \\
\text { (Ha) }\end{array}$ & $\begin{array}{c}\text { Produksi } \\
\text { (Ton) }\end{array}$ & $\begin{array}{l}\text { Produktivitas } \\
\text { (Ton/Ha) }\end{array}$ \\
\hline 1 & Mendahara & & & \\
\hline 2 & Mndahara Ulu & 27 & 170 & 6,30 \\
\hline 3 & Geragai & 160 & 680 & 4,25 \\
\hline 4 & Dendang & 30 & 199 & 6,63 \\
\hline 5 & Muaro Sabak Barat & 93 & 520 & 4,61 \\
\hline 6 & Muara Sabak Timur & 80 & 495 & 5,59 \\
\hline 7 & Kuala jambi & 41 & 250 & 6,10 \\
\hline 8 & Rantau Rasau & 6 & 27 & 4,50 \\
\hline 9 & Berbak & 25 & 166 & 6,64 \\
\hline 10 & Nipah Panjang & 260 & 1.099 & 4,23 \\
\hline \multirow[t]{4}{*}{11} & Sadu & 153 & 655 & 4,28 \\
\hline & & 23 & 156 & 6,78 \\
\hline & Jumlah & 898 & 4.417 & \\
\hline & Rata-rata & 81,63 & 401,54 & 4,92 \\
\hline
\end{tabular}

Sumber : Dinas Pertanian Kabupaten Tanjung Jabung Timur (2015)

Kecamatan Berbak merupakan salah satu wilayah terbesar sebagai produsen jagung di Kabupaten Tanjung Jabung Timur. Namun produktivitasnya berada dibawah rata-rata kecamatan. Adapun jumlah produksi jagung untuk tiap desa dalam kecematan Berbak disajikan pada Tabel 3 .

Tabel 3. Luas Panen, Produksi dan Produktivitas Tanaman Jagung perdesa dalam wilayah kecamatan Berbak Kab. Tanjung Jabung Timur tahun 2015

\begin{tabular}{llccc}
\hline No & \multicolumn{1}{c}{ Desa } & $\begin{array}{c}\text { Luas Panen } \\
(\mathrm{Ha})\end{array}$ & $\begin{array}{c}\text { Produksi } \\
\text { (Ton) }\end{array}$ & $\begin{array}{c}\text { Produktivitas } \\
\text { (Ton/Ha) }\end{array}$ \\
\hline 1 & Kelurahan Simpang Desa & 40 & 168 & 4,20 \\
2 & Rantau Makmur & 100 & 432 & 4,32 \\
3 & Rantau Rasau & 25 & 100 & 4,00 \\
4 & Sungai Rambut & - & - & - \\
5 & Telago Limo & 25 & 105 & 4,20 \\
6 & Rawa Sari & $\mathbf{7 0}$ & $\mathbf{2 9 4}$ & $\mathbf{4 , 2 0}$ \\
\hline & Jumlah & 260 & 1.099 & \\
& Rata-rata & 43,33 & 183,10 & 4,23 \\
\hline
\end{tabular}

Sumber : Data Penyuluh Lapangan (Dinas Pertanian Tanjung Jabung Timur 2015)

Berdasarkan pada Tabel 3 menunjukkan bahwa desa Rantau Makmur memiliki luas panen, produksi dan produktivitas tertinggi dibandingkan dengan desa lainnya yang berda di dalam wilayah kecamatan Berbak. Oleh karena itu maka desa Rantau Makmur dianggap 
Jurnal Media Agribisnis Vol. 2 No. 1 Tahun 2017 Hal 13 - 19

Media Komunikasi Hasil Penelitian Bidang Ilmu Agribisnis

ISSN 2541-6898

paling sesuai untuk dijadikan sebagai daerah penelitian. Permasalahan yang akan dibahas dalam penelitian ini adalah:

1. Bagaimana gambaran kegiatan usaha tani jagung di desa Rantau Makmur kecamatan Berbak kabupaten Tanjung Jabung Timur baik dari aspek hulu onfam dan hilir?

2. Berapa jumlah biaya yang dikeluarkan dalam usaha tani jagung didesa Rantau Makmur kecamatan Berbak kabupaten Tanjung Jabung Timur?

3. Berapa jumlah pendapatan yang diperoleh petani dalam usaha panen jagung didesa Rantau Makmur kecamatan Berbak kabupaten Tanjung Jabung Timur?

Adapun tujuan dari penelitian ini untuk mengetahui gambaran kegiatan usahatani jagung, biaya dalam usahatani jagung, dan pendapatan yang diperoleh petani.

\section{METODOLOGI PENELITIAN}

Penelitian ini dilaksanakan didesa Rantau Makmur kecamatan Berbak kabupaten Tanjung Jabung Timur. Pengumpulan data penelitian ini dilaksanakan mulai pada bulan September sampai dengan Desember 2016. Penelitian dilakukan dengan metode survey dan observasi. Data yang dipergunakan dalam penelitian ini diperoleh dari dua sumber yaitu data primer dan data sekunder. Metode penarikan sampel dalam penelitian ini adalah secara acak sederhana (simple random sampling) (Siegel,1992). Berdasarkan hasil survei diketahui jumlah populasi sebanyak 195 orang petani jagung di desa Rantau Makmur yang terbagi kedalam beberapa kelompok tani. Dan dari total populasi yang ada diambil $15 \%$ sehingga diperoleh sampel sebanyak 30 orang. Data yang diperoleh selanjutnya disederhanakan dengan cara tabulasi, frekuensi dan persentase kemudian di analisis secara deskriptif baik kualitatif maupun kuantitatif.

\section{Identitas Petani Sampel}

\section{HASIL DAN PEMBAHASAN}

Adapun identitas petani yang akan dibahas dalam penelitian ini meliputi umur, tingkat pendidikan, jumlah anggota keluarga, pengalaman usahatani tanaman jagung. Tingkat umur petani berada diantara umur $24-65$ tahun. Petani sampel rata-rata mempunyai Pendidikan rendah yaitu hanya tamat SD. Rata-rata jumlah anggota keluarga petani adalah sebanyak 4 orang. Pengalaman petani dalam berusaha tani sekitar $10-12$ tahun.

\section{Biaya Produksi Usahatani Tanaman Jagung}

Biaya produksi dapat dilihat pada Tabel 4. Berdasarkan Tabel 4 rata-rata komponen biaya tetap yaitu $1,07 \%$. Komponen biaya seperti karung mempunyai persentase yang paling tinggi yaitu 0,50\% dengan jumlah biaya 21.831,10 dibandingkan biaya tetap lainnya. Sedangkan rata-rata komponen biaya variabel yaitu 98,92\%. Biaya upah tenaga kerja mempunyai persentase yang paling tinggi yaitu $46.80 \%$ dengan jumlah biaya 2.028.340 dibandingkan biaya variabel lainnya. Sehingga total dari biaya tetap dan biaya variabel didapat jumlah biaya sebesar 4.322.948,62 dengan persentase $(100,00 \%)$. 
Jurnal Media Agribisnis Vol. 2 No. 1 Tahun 2017 Hal 13 - 19

Media Komunikasi Hasil Penelitian Bidang Ilmu Agribisnis

ISSN 2541-6898

Tabel 4. Rata-rata Komponen Biaya Produksi Petani Sampel Pada Usahatani Tanaman

Jagung di Desa Rantau Makmur Kecamatan Berbak Kabupaten Tanjung Jabung

Timur Tahun 2016

\begin{tabular}{clcc}
\hline No & \multicolumn{1}{c}{$\begin{array}{c}\text { Kompenen Biaya } \\
\text { Produksi }\end{array}$} & $\begin{array}{c}\text { Jumlah Biaya } \\
(\mathrm{Rp} / \mathrm{H} / \mathrm{MT})\end{array}$ & $\begin{array}{c}\text { Persentase } \\
\%\end{array}$ \\
\hline I & Biaya Tetap : & \\
\hline 1 & Tugal & $2.302,17$ & 0,05 \\
2 & Tali Tambang & $6.153,16$ & 0,14 \\
3 & Handsprayer & $7.298,53$ & 0,16 \\
4 & Sabit & $1.773,32$ & 0,04 \\
5 & Karung & $21.831,10$ & 0,50 \\
6 & Parang & 7.084 & 0,16 \\
\hline Jumlah I & & $46.442,29$ & 1,07 \\
\hline II & Biaya Variabel & & \\
\hline 1 & Bibit & 289.875 & 6,68 \\
2 & Pupuk & 852.000 & 19,65 \\
3 & Obat-obat & $552.708,33$ & 12,75 \\
4 & Upah Tenaga Kerja & 2.028 .340 & 46,80 \\
5 & Sewa Power Threser & 553.583 & 12,27 \\
\hline Jumlah II & & $4.276 .506,33$ & 98,92 \\
\hline III. Jumlah I + & & $4.322 .948,62$ & 100,00 \\
II & & & \\
\hline
\end{tabular}

Sumber : Data Primer yang diolah, Tahun 2016

\section{Penerimaan Usahatani Jagung}

Penerimaan usahatani jagung dapat dilihat pada Tabel 5 berikut.

Tabel 5. Rata-rata Produksi, Harga dan Penerimaan pada Usahatani Jagung Desa Rantau Makmur Kecamatan Berbak Kabupaten Tanjung Jabung Timur Tahun 2016.

\begin{tabular}{clr}
\hline No & \multicolumn{1}{c}{ Uraian } & Jumlah \\
\hline 1 & Produksi (Kg/Ha/MT) & \\
2 & Harga (Rp/Kg) & $3.001,75$ \\
3 & Penerimaan (Rp/Ha/MT) & 3.000 \\
\end{tabular}

Sumber : Data primer yang diolah, Tahun 2016

Jumlah penerimaan yang diperoleh oleh petani jagung di Desa Rantau Makmur Kecamatan Berbak merupakan banyaknya jumlah produksi jagung yang dikalikan dengan harga jagung yang dijual. Adapun harga jagung adalah Rp. 3.000/Kg, maka jumlah penerimaan yang diperoleh dengan jumlah produksi sebesar 3.001,75 kg adalah sebesar Rp. $9.005 .250 / \mathrm{Ha} / \mathrm{MT}$. 
Jurnal Media Agribisnis Vol. 2 No. 1 Tahun 2017 Hal 13 - 19

Media Komunikasi Hasil Penelitian Bidang Ilmu Agribisnis

ISSN 2541-6898

\section{Pendapatan Usahatani Tanaman Jagung}

Tabel 6. Rata-rata Penerimaan, Biaya Produksi dan Pendapatan Petani Sampel pada Usahatani Tanaman Jagung di Desa Rantau Makmur Kecamatan Berbak Kabupaten Tanjung Jabung Timur Tahun 2016

\begin{tabular}{clc}
\hline No & \multicolumn{1}{c}{ Uraian } & Jumlah $(\mathrm{Rp} / \mathrm{Ha} / \mathrm{MT})$ \\
\hline 1 & Penerimaan & 9.005 .250 \\
2 & Biaya Produksi & $4.322 .948,62$ \\
3 & Pendapatan & $4.682 .301,37$ \\
\hline
\end{tabular}

Sumber : Data primer yang diolah tahun 2016

Berdasarkan dari Tabel 2 di atas, terlihat bahwa rata-rata pendapatan yang diterima petani sampel dari usahatani tanaman jagung di daerah penelitian adalah sebesar Rp. 4.682.301,37/Ha/MT. Berdasarkan angka pendapatan tersebut maka jumlah pendaatan untuk setiap bulannya adalah sebesar Rp. 156.076,71. Artinya jika rata-rata jumlah anggota keluarga sebanyak 3 orang, maka jumlah pendapatan yang diperoleh adalah sebesar Rp. 468.230,1/Orang/bulan. Sementara nilai upah umur regional (UMR) di Kabupaten Tanjung Jabung Timur adalah sebesar Rp. 2.020.000/orang/bulan. Berdasarkan hal tersebut maka dapat dikatakan bahwa petani jagung di Desa Rantau Makmur Kecamatan Berbak Kabupaten Tanjung Jabung Timur masih tergolong belum sejahtera.

\section{KESIMPULAN}

Berdasarkan hasil penelitian dan pembahasan dapat ditarik kesimpulan sebagai berikut:

1. Gambaran kegiatan usahatani jagung di Desa Rantau Makmur Kecamatan Berbak Kabupaten Tanjung Jabung Timur meliputi 3 aspek utama yakni aspek hulu (persiapan sarana dan prasarana produksi) melipui persiapan alat-alat pertanian beserta jumlah kebutuhannya.

2. Biaya yang dikeluarkan dalam usahatani mulai dari aspek hulu onfam hingga hilir meliputi biaya tetap dan biaya tidak, biaya tidak tetap merupakan biaya tertinggi yang dikeluarkan oleh para petani jagung, rata-rata biaya tetap sebesar Rp. 4.276.506,33 sedangkan biaya tetap yang dikeluarkan rata-rata sebesar Rp. 46.442,29.

3. Pendapatan yang diperoleh petani dalam usahatani jagung di Desa Rantau Makmur Kecamatan Berbak Kabupaten Tanjung Jabung Timur cukup tinggi dengan masa tanam yang relatif singkat. Rata-rata hasil produksi jagung sebesar Rp. 3.001,75 Kg/Ha/MT dengan harga jual Rp. $3.000 / \mathrm{Kg}$, rata-rata penerimaan adalah sebesar Rp. 9.005.250/Ha/MT dan rata-rata pendapatan adalah sebesar Rp. 4.682.301,37/Ha/MT 
Jurnal Media Agribisnis Vol. 2 No. 1 Tahun 2017 Hal 13 - 19

Media Komunikasi Hasil Penelitian Bidang Ilmu Agribisnis

ISSN 2541-6898

\section{DAFTAR PUSTAKA}

Biro Badan Pusat Statistik. 2015. Jambi Dalam Angka. BPS. Jambi.

Hernanto, F. 1996. Ilmu Usahatani. Penebar Swadaya. Jakarta.

Husein Umar. 2007. Metodelogi penelitian untuk Skripsi Dan Tesis Bisnis. PT. Raja Grafindo Persada. Jakarta.

Nazir, M. 1999. Metode Penelitian. Ghalia Indonesia jakarta.

Siegel, Sidney. 1992. Statistik Nonparametrik untuk Ilmu-Ilmu Sosial. Gramedia. Jakarta.

Soekartawi. 1990. Teori Ekonomi Produksi dengan Pokok Bahasan Analisis Fungsi Cob-

Dounglas. PT. Rajagrafindo Persada. Jakarta. 